\title{
Comparative Analysis of Free Natural Convection Heat Transfer on Rectangular and Triangular Fins with and without Perforation
}

\author{
Ogie Nosa Andrew, and Joel Oluwayomi Oyejide,
}

\begin{abstract}
The importance of heat transfer by free natural convection can be found in many engineering applications such as energy transfer in buildings, solar collectors, nuclear reactors and electronic packaging. In this research work, we carried out the investigation and comparative analysis of heat transfer by natural convection on rectangular and triangular fins with and without circular perforation. A total of six (6) specimens were used. Other materials that were used in this research work include four digital thermometers, one heating element, four thermocouple K-types and a power source. The fins used in this research work were welded to a cylindrical pipe which served as the heat sink. The heat supplied was maintained at $250^{\circ} \mathrm{C}$ and the temperature drop through the fin was recorded for duration of 30 minutes with intervals of 5minutes. It was observed that the temperature dropped more rapidly with the triangular fins than the rectangular fin. Also, the rate of heat dissipation increase with a corresponding increase in the number of perforation.
\end{abstract}

Index Terms-Rectangular and Triangular Fins; Perforated; Natural Convection; Heat Transfer, Comparison.

\section{INTRODUCTION}

Heat transfer is a thermal energy which occurs in transit as a result of temperature difference. The modes of heat transfer are conduction, convection and radiation [1]. Fins or extended surface are thin components attached to larger body or structure which are used to improve convective heat transfer in a wide range of engineering application and offers a practical means of achieving large total surface area [2]. The fin is applied where heat transfer coefficient is not large enough. Heat transfer takes place by means of conduction and convection in fin arrangement [3]-[4]. Heat transfer is very important for any industry; nevertheless, better fins are required for optimum heat dissipation from the primary surface. They have a variety of application in the industry due to their excellent heat transfer performance. They can be used in the cooling of electronic components, in the cooling of gas turbine blades and heat exchangers etc. Materials selection and design of any particular type of fin is very vital in engineering application. Fins selections are based on maximum heat transfer rate and it depends on the shape or geometry of fin [5].

Publised on May 27, 2018.

N.O. Ogie is with the Department of Mechanical Engineering, Petroleum Training institute, Effurun, Nigeria (ogie_na@pti.edu.ng).

J.O. Oyejide is with the Department of Mechanical Engineering, Federal University of Petroleum Resources, Effurun, Nigeria (Oyejide.joel@fupre.edu.ng).
Based upon the cross sectional area type, fins are of different types. They include; rectangular fin, triangular fin, trapezoidal fin, parabolic fin or cylindrical fin [6]. Rectangular fin is a common type of fin which is used in many places. Their common usage is as a result of ease in design and stress-free manufacture. The rate of heat transfer from a fin base decreases along the tip of the fin [7]. Fewer materials are used for triangular fin unlike rectangular fin [8]. In parabolic fins heat transfer rate per unit volume is slightly greater than triangular fin. Fin performance can be measured by using the effectiveness of fin, thermal resistance and efficiency. However, when the surface area of an object is increased, there is bound to be an increase in the rate of heat transfer between the object and the environment [9]. With fins, heat energy is broken into fractions and dissipated at a faster rate. Various optimizations have been done on fins to increase the rate of heat transfer. Optimization in the area of fin geometry (shape, size, array, height) as well as perforation on the fin plate has proven to have an effect on the heat transfer coefficient [10].

Although, there are a lot of existing work on fins, but enough has not been done on the comparison of rectangular and triangular with and without perforation. Kundu and Das [11] investigated a two-dimensional rectangular fin with arbitrary variable heat transfer coefficient on the fin surface using a Fourier series approach. Kang and Look analyzed the trapezoidal fins of various slopes using the analytical method [12]. Abrate and Newnham presented heat conduction in an array of triangular fins with an attached wall using the finite element method [13]. Laor and Kalman studied the optimization of the three shapes (rectangular, triangular and parabolic) for the three types of fins (longitudinal, spine and annular) using the general heat balance differential equation [14]. Chung et al. dealt with the optimum design of convective longitudinal fins of a trapezoidal profile using the general differential equation based on the energy balance [15]. Kang, and Look investigated the optimum dimensions of rectangular fins and cylindrical pin fins [12].

\section{MATERIALS AND METHODS}

In this research work, aluminium material was selected based on the following:

i. Weight

ii. Thermal conductivity

iii. Weldability

iv. Workability

v. Durability 


\section{vi. Cost}

vii. Machinability

Aluminium is generally light in weight with a density of $2700 \mathrm{~kg} / \mathrm{m}^{3}$, and it equally possesses a good corrosion resistance. It can be moulded into casts, worked with machine tools and made into sheets metal, thus making it useful for a wide variety of application. It has a melting point of $660^{\circ} \mathrm{C}$ and is a good thermal and electrical conductor. Its thermal conductivity is approximately four times greater than steel. This necessitates higher heat input when fusion welding aluminum.

\section{A. Data Analysis for Rectangular Fin}

Two different fins (i.e., with perforation and without perforation) via triangular fin and rectangular fin were used in this research work. These were used as a reference which was provided as a basis for comparison. The heat losses through the fins were calculated using (1).

$$
Q=(h P K A)^{0.5} \times \theta_{S}\left[\frac{\frac{h}{m k}+\text { tanhml }}{1+\frac{h}{m k} \operatorname{tanhml} l}\right]
$$

where,

$\mathrm{h}=$ Convective heat transfer coefficient of air $=83 \mathrm{~W} / \mathrm{m}^{2}$ ${ }^{0} \mathrm{C}$

$\mathrm{A}=$ Cross sectional area of fin

$\mathrm{W}=$ Width of the fin plate $=94 \mathrm{~mm}=0.094 \mathrm{~m}$

$\mathrm{t}=$ Thickness of fin plate $=3 \mathrm{~mm}=0.003 \mathrm{~m}$

$\mathrm{L}=$ Length of the fin plate $=130 \mathrm{~mm}=0.13 \mathrm{~m}$

$\mathrm{M}=$ Fin parameter

But,

$\mathrm{A}=0.094 \times 0.003=0.000282 \mathrm{~m}^{2}$

Also,

$\mathrm{P}=$ Perimeter of the fin plate $=2(\mathrm{~W}+\mathrm{t})=2(0.094 \mathrm{x}$ $0.003)=0.194 \mathrm{~m}$

Thermal Conductivity of Aluminium $=167 \mathrm{~W} / \mathrm{m}^{0} \mathrm{C}$

$$
M=\sqrt{\frac{h p}{K A}}=\sqrt{\frac{83 \times 0.194}{167 \times 0.000282}}=18.49 \mathrm{~m}^{-1}
$$

where,

$\Theta_{\mathrm{s}}=$ Temperature difference between initial condition $\left(\mathrm{T}_{1}\right)$ and final condition $\left(\mathrm{T}_{2}\right)$ at $5 \mathrm{mins}$ and $30 \mathrm{mins}$ respectively

\section{B. Experimental Procedure}

A total of six fins comprising of three rectangular and triangular fins each were used for this research work. These fins were made out from a flat aluminium sheet ( $4 \mathrm{~mm}$ thick) using measuring tape, scriber, steel rule, hacksaw, vice, and hand file. Furthermore, a cylindrical pipe made of aluminum material was used as the heat sink. Calculation was done to ensure that the surface area of the rectangle fin was equal to that of the triangular fin for even comparison and this formed the basis for selecting suitable dimensions for the machining of the fins.

\section{Assumption}

In performing this experiment, the following assumptions were considered

i. One dimensional heat flow

ii. Uniform supply of power

iii. Perforation distance is uniform across the surface
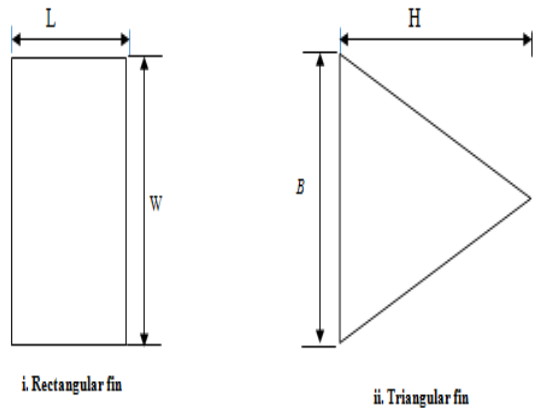

$A_{R}=L B$

$A_{T}=\frac{1}{2} B H$

where,

$\mathrm{L}=$ Length of rectangle $=94 \mathrm{~mm}$

$\mathrm{W}=$ Width of rectangle $=130 \mathrm{~mm}$

$\mathrm{B}=$ Breadth of triangle $=184 \mathrm{~mm}$

$\mathrm{H}=$ Height of triangle

\section{Assumption}

For this analysis, the width (W) of the rectangular fin is equal to the base (B) of the triangular fin.

That is;

Area of a rectangle $=$ Area of a Triangle

$\mathrm{L} \times \mathrm{W}=1 / 2 B \times H$

But,

$\mathrm{W}=\mathrm{B}$

$\mathrm{L}=1 / 2 \times H$

$\mathrm{H}=2 \mathrm{~L}$

Therefore,

Area of the triangle $=1 / 2 \mathrm{~B} \times 2 \mathrm{~L}=1 / 2 \times 130 \times(2 \times 94)=$ $12220 \mathrm{~mm} 2=12.2 \mathrm{~m}^{2}$

Fig. 1 shows the fin without perforation, and Fig. 2 shows the fin with perforation.

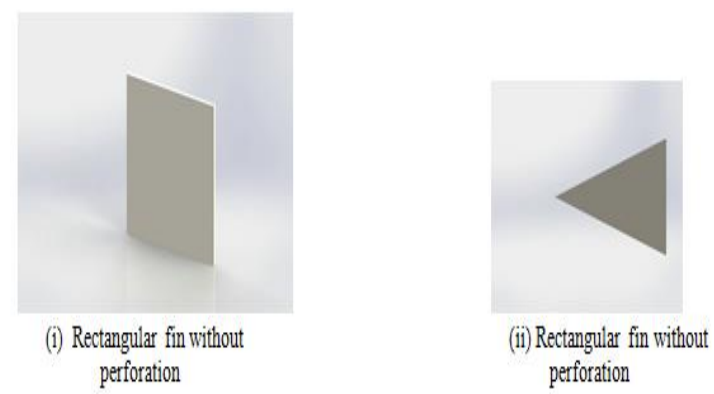

Fig.1. Fin without perforation
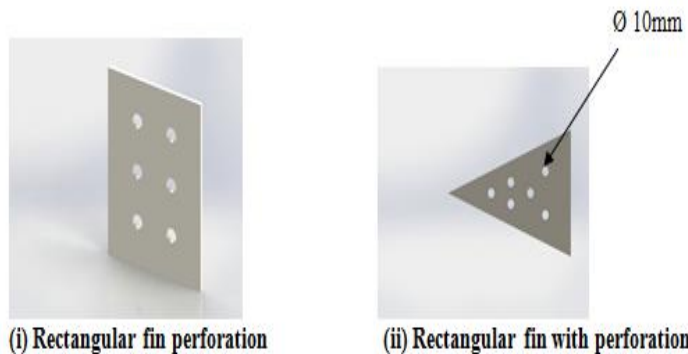

Fig.2. Rectangular and triangle fin with six perforations 
The fins were fused to the cylindrical pipe by Gas Tungsten Arc Welding (GTAW). The metal surfaces were properly prepared before the welding operation was done to ensure that the weld is homogenous throughout. Other materials used for the experiment are cartridge type heating element having a power rating of $750 \mathrm{~W} 220 \mathrm{~V}$, four digital thermometer $0^{\circ} \mathrm{C}-660^{\circ} \mathrm{C}$, stopwatch, four type $\mathrm{K}$ thermocouple wires, power source. The analysis was done in a suitable electrical laboratory with controlled air influx. The welded part was fitted in the circular groove made on a rectangular block (insulation material). The heating element was also fitted carefully into the whole drilled on the centre of the block. Each of the thermocouple wires were connected to the digital thermometer and the probe (lead) were attached to the fin being analysed. One of the thermocouple was placed on the heat sink so as to measure the heat supplied. The other three were evenly positioned across the fin. As power is delivered to the heating element, the temperature at the sink began to rise gradually until it got to $215^{\circ} \mathrm{C}$ where the power supply was stopped. This supply temperature was maintained through the experiment due to the fact that Aluminium has a melting point of $660^{\circ} \mathrm{C}$. The heat is allowed to transfer to the fin until the fin temperature rises to the maximum. At this point, the recording of the temperature fall across the fin began and this is done for every five minute interval until it gets to 30mins. Same procedure is repeated for the rest fin and all readings tabulated. The experimental setup is shown in Fig. 3 .

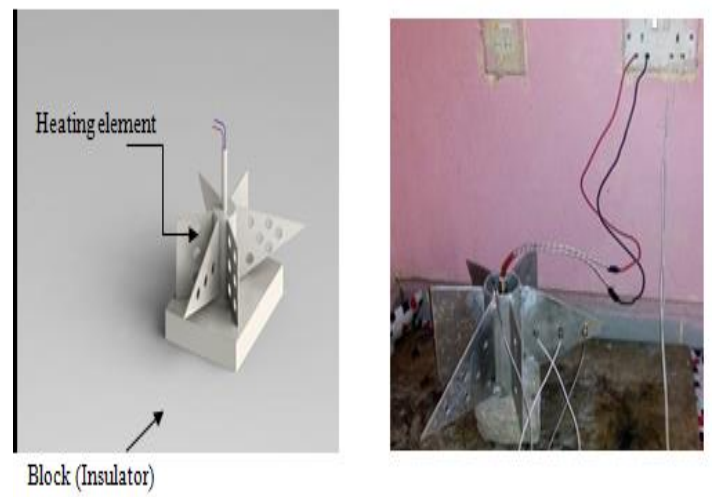

(i) Photograph of the welded structure connected to power supply

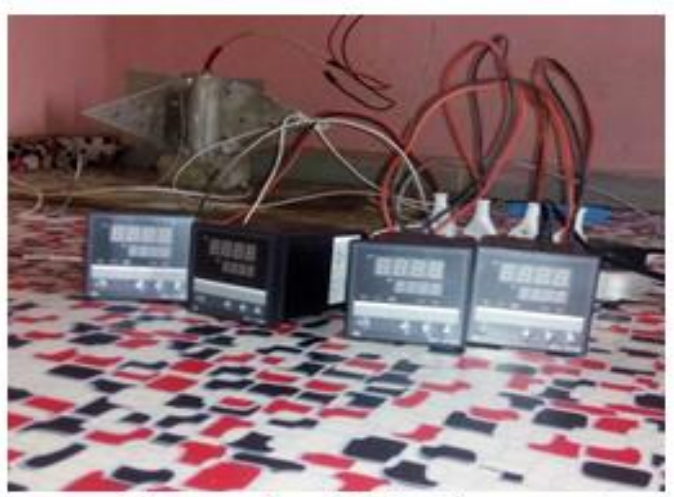

Photograph of digital thermometers Fig.3. Experimental Set-Up

\section{RESULTS AND DISCUSSION}

In this research work, we carried out comparative analysis of free natural convection heat transfer on rectangular and triangular fins with and without perforation. The experiment was carried out to determine the rate of heat transfer from different fin geometries as well as the effect of perforation as heat transfer enhancement. In the experimentation, two geometric fins (rectangular and triangular shape) which are made of aluminium material were used. Also, the effect of the number of circular perforation on the fin plate was analysed and compared. The results gotten from the analysis are represented in Table I-Table IV.

$$
T_{m}=\frac{T_{1}+T_{2}+T_{3}}{3}
$$

\begin{tabular}{cccccc}
\multicolumn{5}{c}{ TABLE I: RECTANGULAR Fin (CONTROL SPECIMEN) } \\
\hline S/N & $\begin{array}{c}\text { Time } \\
(\text { Min })\end{array}$ & \multicolumn{4}{c}{ Temperature $\left({ }^{0} \mathrm{C}\right)$} \\
\hline & & $\mathrm{T}_{1}$ & $\mathrm{~T}_{2}$ & $\mathrm{~T}_{3}$ & $\mathrm{~T}_{\mathrm{m}}$ \\
1 & 5 & 38.00 & 39.00 & 35.00 & 37.33 \\
2 & 10 & 37.00 & 38.00 & 34.00 & 36.33 \\
3 & 15 & 36.00 & 36.00 & 33.00 & 35.00 \\
4 & 20 & 35.00 & 34.00 & 33.00 & 34.00 \\
5 & 25 & 31.00 & 33.00 & 33.00 & 32.33 \\
6 & 30 & 30.00 & 30.00 & 31.00 & 30.33 \\
\hline
\end{tabular}

\begin{tabular}{cccccc}
\multicolumn{5}{c}{ TABLE II: TRIANGUlar FIN (CONTROL SPECIMEN) } \\
\hline \hline S/N & $\begin{array}{c}\text { Time } \\
(\mathrm{min})\end{array}$ & \multicolumn{4}{c}{ Temperature $\left({ }^{\circ} \mathrm{C}\right)$} \\
\hline & & $\mathrm{T}_{1}$ & $\mathrm{~T}_{2}$ & $\mathrm{~T}_{3}$ & $\mathrm{~T}_{\mathrm{m}}$ \\
1 & 5 & 35.00 & 37.00 & 34.00 & 35.33 \\
2 & 10 & 33.00 & 34.00 & 31.00 & 32.67 \\
3 & 15 & 31.00 & 31.00 & 29.00 & 30.33 \\
4 & 20 & 28.00 & 30.00 & 28.00 & 28.67 \\
5 & 25 & 27.00 & 29.00 & 27.00 & 27.67 \\
6 & 30 & 28.00 & 27.00 & 27.00 & 27.33 \\
\hline \hline
\end{tabular}

\begin{tabular}{ccrrrr}
\multicolumn{6}{c}{ TABLE III: RECTANGULAR FIN (3 PERFORATION) } \\
\hline \hline S/N & $\begin{array}{l}\text { Time } \\
(\mathrm{min})\end{array}$ & \multicolumn{5}{c}{ Temperature $\left({ }^{\circ} \mathrm{C}\right)$} \\
\hline & & $\mathrm{T}_{1}$ & $\mathrm{~T}_{2}$ & $\mathrm{~T}_{3}$ & $\mathrm{~T}_{\mathrm{m}}$ \\
1 & 5 & 44.00 & 42.00 & 43.00 & 43.00 \\
2 & 10 & 42.00 & 41.00 & 41.00 & 41.33 \\
3 & 15 & 40.00 & 40.00 & 39.00 & 39.67 \\
4 & 20 & 38.00 & 38.00 & 37.00 & 37.67 \\
5 & 25 & 36.00 & 36.00 & 36.00 & 36.00 \\
6 & 30 & 34.00 & 32.03 & 33.00 & 33.00 \\
\hline \hline
\end{tabular}

TABLE IV: TRIANGULAR FIN (3 PERFORATION)

\begin{tabular}{cccccc}
\hline S/N & $\begin{array}{c}\text { Time } \\
(\mathrm{min})\end{array}$ & \multicolumn{4}{c}{ Temperature $\left({ }^{0} \mathrm{C}\right)$} \\
\hline & & $\mathrm{T}_{1}$ & $\mathrm{~T}_{2}$ & $\mathrm{~T}_{3}$ & $\mathrm{~T}_{\mathrm{m}}$ \\
1 & 5 & 44.00 & 43.00 & 40.00 & 42.33 \\
2 & 10 & 41.00 & 40.00 & 37.00 & 39.33 \\
3 & 15 & 36.00 & 36.00 & 35.00 & 35.67 \\
4 & 20 & 33.00 & 33.00 & 31.00 & 32.33 \\
5 & 25 & 30.00 & 30.00 & 31.00 & 30.33 \\
6 & 30 & 28.00 & 28.00 & 29.00 & 28.67 \\
\hline \hline
\end{tabular}

TABLE V: TRIANGULAR FIN (6 PERFORATION)

\begin{tabular}{|c|c|c|c|c|c|}
\hline \multirow[t]{2}{*}{$\mathrm{S} / \mathrm{N}$} & \multirow[t]{2}{*}{$\begin{array}{l}\text { Time } \\
(\min )\end{array}$} & \multicolumn{4}{|c|}{ Temperature $\left({ }^{0} \mathrm{C}\right)$} \\
\hline & & $\mathrm{T}_{1}$ & $\mathrm{~T}_{2}$ & $\mathrm{~T}_{3}$ & $\mathrm{~T}_{\mathrm{m}}$ \\
\hline 1 & 5 & 40.00 & 43.00 & 42.00 & 41.67 \\
\hline 2 & 10 & 37.00 & 40.00 & 39.00 & 38.67 \\
\hline 3 & 15 & 34.00 & 37.00 & 36.00 & 35.67 \\
\hline 4 & 20 & 31.00 & 34.00 & 33.00 & 32.67 \\
\hline 5 & 25 & 29.00 & 31.00 & 31.00 & 30.33 \\
\hline 6 & 30 & 27.00 & 29.00 & 28.00 & 28.00 \\
\hline
\end{tabular}




\begin{tabular}{cccccc}
\multicolumn{5}{c}{ TABLE VI: RECTANGULAR FIN (6 PERFORATION) } \\
\hline \hline S/N & $\begin{array}{c}\text { Time } \\
(\mathrm{min})\end{array}$ & \multicolumn{4}{c}{ Temperature $\left({ }^{0} \mathrm{C}\right)$} \\
\hline & & $\mathrm{T}_{1}$ & $\mathrm{~T}_{2}$ & $\mathrm{~T}_{3}$ & $\mathrm{~T}_{\mathrm{m}}$ \\
1 & 5 & 44.00 & 43.00 & 42.00 & 43.00 \\
2 & 10 & 41.00 & 40.00 & 41.00 & 40.67 \\
3 & 15 & 40.00 & 38.00 & 37.00 & 38.33 \\
4 & 20 & 36.00 & 34.00 & 33.00 & 34.33 \\
5 & 25 & 32.00 & 30.00 & 30.00 & 30.67 \\
6 & 30 & 29.00 & 29.00 & 27.00 & 28.67 \\
\hline \hline
\end{tabular}

\section{A. Control Specimen (Without Perforation)}

For this analysis, every other value remains the same expect the temperature difference.

$$
\begin{aligned}
& Q \\
& =(83 \times 0.194 \times 167 \times 0.000282)^{0.5} \\
& \times(37.33-30.33)\left[\frac{\frac{83}{18.49 \times 167}+\tan (83 \times 18.49 \times 0.13)}{1+\frac{83}{18.49 \times 167} \tan (83 \times 18.49 \times 0.13)}\right] \\
& =2.301 \mathrm{~W}
\end{aligned}
$$

Therefore, the heat loss $(\mathrm{Q})$ is $2.301 \mathrm{~W}$

Fin efficiency $\eta=2.301 /(83 \times 0.000282 \times 7)=14.044 \%$

\section{B. Rectangular Fin with Three Perforations}

$Q=(83 \times 0.194 \times 167 \times 0.000282)^{\Lambda} 0.5 \times(43.00-$ $33.00)\left[\frac{\frac{83}{18.49 \times 167}+\tan (83 \times 18.49 \times 0.13)}{1+\frac{83}{18.49 \times 167} \tan (83 \times 18.49 \times 0.13)}\right]=3.288 \mathrm{~W}$

Thus the heat loss $(\mathrm{Q})$ is $3.288 \mathrm{~W}$

Fin efficiency $\eta=3.2875 /(83 \times 0.000282 \times 10)=14.045 \%$

\section{Rectangular Fin with Six Perforations}

$$
Q=(83 \times 0.194 \times 167 \times 0.000282)^{\wedge} 0.5 \times(41.67-
$$

28.66) $\left[\frac{\frac{83}{18.49 \times 167}+\tan (83 \times 18.49 \times 0.13)}{1+\frac{83}{18.49 \times 167} \tan (83 \times 18.49 \times 0.13)}\right]=4.277 \mathrm{~W}$

Thus the heat loss $(\mathrm{Q})$ is $4.277 \mathrm{~W}$

Fin efficiency $\eta=4.277 /(83 \times 0.000282 \times 13.01)=$ $14.047 \%$

The results obtained reveal that in the case of control specimen, triangular fins offer more enhancement of heat transfer as compared to rectangular fins (Fig. 4). Furthermore, as the number of perforation increases, the temperature drop for triangular fins occurs faster than the rectangular fin (Fig. 5 and Fig. 6). From the graphs plotted and calculation on the gradient, triangular fins was found to offer a faster cooling rate as compared to rectangular fins for every equal number of perforations. The following result backs this up; rectangular fin without perforation have a cooling rate of $0.28^{\circ} \mathrm{C} / \mathrm{min}$ while triangular fins without perforation has a cooling rate of $0.32^{\circ} \mathrm{C} / \mathrm{min}$. Rectangular fin with three perforation have a cooling rate of $0.40^{\circ} \mathrm{C} / \mathrm{min}$ while triangular fins with three perforation have a cooling rate of $0.55^{\circ} \mathrm{C} / \mathrm{min}$. Rectangular fins with six perforation have a cooling rate of $0.55^{\circ} \mathrm{C} / \mathrm{min}$ while Triangular fins with six perforation have a cooling rate of $0.57^{\circ} \mathrm{C} / \mathrm{min}$. Also, the progressive decline of the cooling rate across the fin can be seen in the linear regression line equation. The slope $(\mathrm{m})$ increases in the negative direction as the temperature fall with time. In comparison of the triangular fin with the rectangular fin, it can be seen that the triangular fin performs better and gives good heat transfer result.

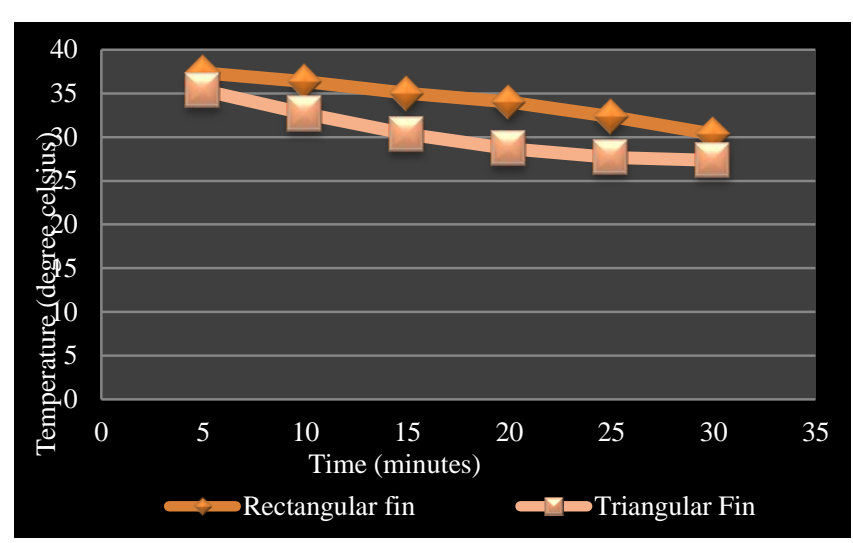

Fig. 4. Graph of Temperature versus Time for Rectangular and Triangular fin without perforation

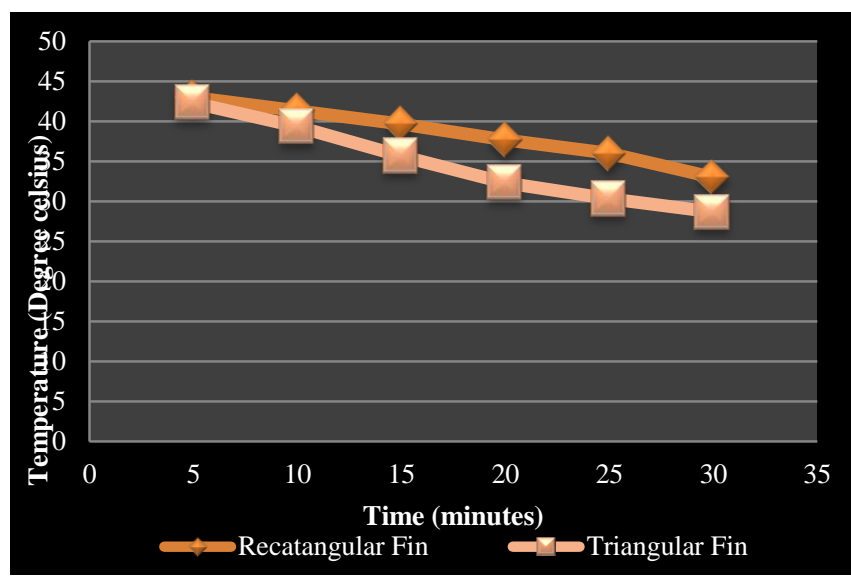

Fig. 5. Graph of Temperature versus Time for Rectangular and Triangular fin with perforation (3 Perforation)

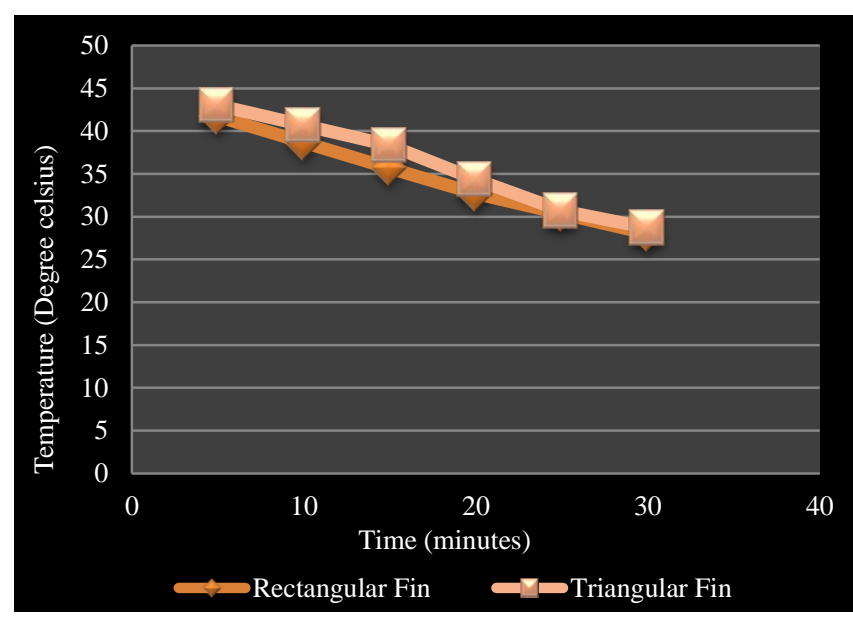

Fig. 6. Graph of Temperature versus Time for Rectangular and Triangular fin with perforation (6 Perforation)

From the graphs plotted above, the cooling rate $\left({ }^{0} \mathrm{C} / \mathrm{min}\right)$ for each specimen (fin) can be determined by calculating for the slope (gradient) of each graph using the formula given below;

$$
G=\frac{d y}{d x}=\frac{y 2-y 1}{x 2-x 1}
$$

The equation governing the linear regression line produced from the curved is given as;

$$
y=m x+c
$$


where,

$\mathrm{y}=$ Temperature $\left({ }^{0} \mathrm{C}\right)$ on the vertical axis

$\mathrm{x}=$ Time (minute) on the horizontal axis

$\mathrm{m}=$ slope (gradient)

$\mathrm{c}=$ intercept

D. Rectangular fin without perforation (control specimen)

$G=\frac{37.33-30.33}{30-5}=0.28^{\circ} \mathrm{C} / \mathrm{min}$

\section{E. Triangular fin without perforation (control specimen)}

$G=\frac{35.33-27.33}{30-5}=0.32^{0} \mathrm{C} / \mathrm{min}$

F. Rectangular fin with three (3) perforations 7

$\mathrm{G}=\frac{43.00-33.00}{30-5}=0.40^{\circ} \mathrm{C} / \mathrm{min}$

G. Triangular fin with three (3) perforations

$G=\frac{42.33-28.67}{30-5}=0.55^{0} \mathrm{C} / \mathrm{min}$

H. Rectangular fin with six (6) perforations

$G=\frac{41.67-28.00}{30-5}=0.55^{\circ} \mathrm{C} / \mathrm{min}$

I. Triangular fin with six (6) perforations

$$
\mathrm{G}=\frac{43.00-28.67}{30-5}=0.57^{\circ} \mathrm{C} / \mathrm{min}
$$

\section{CONCLUSION}

From the experimental data collected and analysis through graphs and calculations, it can be deduced that triangular fin without perforation is more effective and efficient in transferring heat when compared to rectangular fin without perforation. It is also seen that with increase in perforation, triangular fin gives better heat transfer enhancement than rectangular fin. Generally, perforation on fin plates increases the surface area for effective heat transfer and reduces the weight of the components with regards to industrial application.

\section{RECOMMENDATIONS}

Having carried out the research work on the comparative analysis of free natural convection heat transfer on rectangular and triangular fins with and without perforation, the following recommendations were made;

i. In order to ensure optimum accuracy of result and effective comparison, the number of perforation on the plate should be increased.

ii. The perforation geometry should be varied and compared such as triangular perforation, square perforation, trapezium, etc.

iii. Aside aluminium, other materials should be analysed to ascertain their performance in heat transfer.

iv. Other fin geometries should be compared.

v. Finite element analysis should be used for further work

\section{REFERENCES}

[1] S. Mirapalli, and P.S. Kishore, "Fin Heat Transfer Analysis on a Triangular Fin.", International Journal of Engineering Trends and Technology, 19, 279-282, 2015

[2] S.S. Sane, N.K. Sane, G.V. and A. Parishwad, "Computational Analysis of Horizontal Rectangular Notched Fin Arrays Dissipating Heat by Natural Convection" 5th European Thermal-Sciences Conference, The Netherlands, 2008

[3] D. Bhanja, AND b. Kundu, B, "Thermal Analysis of a Constructed Tshaped Porous Fin with Radiation Effects", International Journal of Refrigeration, 34, 1483, 2011

[4] S.H. Barhatte, "Experimental and Computational Analysis and Optimization for Heat Transfer through Fins with Triangular Notch", International Journal of Emerging Technology and Advanced Engineering, 2(7), 23-32, 2012

[5] World Academy Science Conference on Engineering and Technology, Mechatronic and Manufacturing Engineering, South Africa, 2014

[6] B.T.F. Chung, and J.R. Iyer, "Optimum Design of Longitudinal Rectangular Fins and Cylindrical Spines with Variable Heat Transfer Coefficient", Heat Transfer Engineering, 14(1), 31-42, 1993

[7] H.S. Kang, and D.C. Look, "Optimization of Thermally and Geometrically Asymmetric Trapezoidal Fins", AIAA J. of Thermophysics and Heat Transfer, vol. 18(1), 52-57, 2004

[8] C. Casarosa, and A. Franco, "On the Optimum Thermal Design of Individual Longitudinal Fins with Rectangular Profile", Heat Transfer Engineering, 22 (1), 51-71, 2001

[9] S.W. Ma, A.I. Behbahani, and Y.G. Tsuei, "Two-Dimensional Rectangular Fin with Variable Heat Transfer Coefficient”, Int. J. of Heat and Mass Transfer, 34 (1), 79-85, 2001

[10] R.H. Yeh, "An Analytical Study of the Optimum Dimensions of Rectangular Fins and Cylindrical Pin Fins", Int. J. Heat Mass Transfer, 40(15), 3607-3615, 1997

[11] B. Kundu, and P.K. Das, "Performance Analysis and Optimization of Eccentric Annular Disk Fins," ASME J. of Heat Transfer, 121,128135, 1999

[12] H.S. Kang, and D.C. Look, "Two Dimensional Trapezoidal Fins Analysis", Computational Mechanics, 19,247-250, 1997

[13] A S. Abrate, and P. Newnham, "Finite Element Analysis of Triangular Fins Attached to a Thick Wall", Computers and Structures, 57(6), 945-957, 1995

[14] K. Laor, and H. Kalman, "The Effect of Tip Convection on the Performance and Optimum Dimensions of Cooling Fins", Int. Comm. Heat Mass Transfer, 19, 569-584, 1992

[15] B.T.F. Chung, M.H. Abdalla, and F. Liu, "Optimization of Convective Longitudinal Fin of Trapezoidal Profile," Chem. Eng. Comm., 80, 211-223, 1989. 